\title{
A global consensus on the prevention and management of nutritional rickets: How does this change policy in South Africa?
}

Globally, rickets secondary to vitamin D deficiency and/or low dietary calcium intake remains a significant public health problem, not only in resource-poor countries but also in those that are better resourced, despite effective means being available for its prevention and treatment. The disease may have both short- and long-term consequences for the affected child, the latter frequently persisting into adulthood.

Although there have been renewed scientific interest and focus on the role of vitamin D status in health and disease, the same cannot be said for the implementation of public health guidance for the eradication of rickets due to vitamin D deficiency and/or low dietary calcium intake in our most vulnerable populations. Recently, there have been a number of international initiatives to address these issues. ${ }^{[1]}$ At the beginning of this year, a consensus group comprising representatives from paediatric endocrine societies, nutrition societies and individual experts published a consensus statement on the prevention and management of nutritional rickets in the Journal of Clinical Endocrinology and Metabolism ${ }^{[2]}$ and Hormone Research in Paediatrics. ${ }^{[3]}$ This consensus statement was the culmination of a review of the literature by five task teams and a three-day workshop held in 2014. It is hoped that this statement will be the beginning of a concerted effort to convince relevant international organisations and national governments that the eradication of nutritional rickets is not only feasible but also of considerable benefit to child health globally.

At the outset, it should be emphasised that the recommendations pertain only to the prevention and treatment of nutritional rickets and do not attempt to address other possible clinical effects of a poor vitamin D status. It is not possible in this editorial to highlight all the recommendations made by the group, but there are a number of recommendations that are central to the global prevention of rickets that need to be emphasised:

- Vitamin $\mathrm{D}$ deficiency is defined by a 25 -hydroxyvitamin $\mathrm{D}$ (25OHD) of $<30 \mathrm{nmol} / \mathrm{L}$.

- For children $>12$ months of age, a dietary calcium intake of $<300 \mathrm{mg} /$ day increases the risk of rickets independent of serum $25 \mathrm{OHD}$ levels.

- All infants $<12$ months of age should be supplemented with vitamin D 400 IU/day, irrespective of the mode of feeding.

- Children >12 months of age should be considered for supplementation (600 IU/day) if they are at risk of vitamin D deficiency by being a member of a high-risk community or having social or environmental factors that reduce their access to skin synthesis of vitamin $\mathrm{D}$ or to dietary vitamin $\mathrm{D}$ intake.

- In healthy children, routine 25OHD screening is not recommended and therefore there is no specific threshold for vitamin D supplementation in this population.

- All pregnant women should be supplemented with vitamin D $600 \mathrm{IU} /$ day to reduce the risk of neonates being born with a low 25OHD concentration, but evidence does not suggest that dietary calcium requirements are increased during pregnancy and lactation.

- Fortification of staple foods should be considered as a means of improving the vitamin D status of populations.

The most important question to be asked by South African (SA) child health professionals is how do these recommendations relate to the situation in SA? Certainly, what little information there is available would suggest that the recommendations are very relevant. Firstly, despite the good average daily hours of sunshine that most areas of the country experience throughout the year, vitamin $\mathrm{D}$ production through ultraviolet radiation is limited in the southern-most regions during the autumn and winter months from April through September. ${ }^{[4]}$ Secondly, symptomatic vitamin D deficiency (mainly hypocalcaemia) is not an uncommon presentation in young infants at Chris Hani Baragwanath Academic Hospital in Johannesburg, and severe rickets and bone deformities are frequently seen in toddlers and young children living in the overcrowded high-rise buildings of the inner city region of Johannesburg (unpublished data). Clear seasonal variations in circulating 25OHD have been reported in adults from both Johannesburg ${ }^{[5]}$ and CapeTown, ${ }^{[6]}$ and the prevalence of vitamin $\mathrm{D}$ deficiency has been reported to be high in Indian females living in Johannesburg ${ }^{[5]}$ and in blacks living in Cape Town. ${ }^{[6]}$

Because of the high prevalence of rickets in infants in Cape Town and to a lesser extent in Johannesburg in the mid-1900s, vitamin D supplementation (400 IU/day) of all infants during the first 12 months of life was routine practice in primary healthcare clinics; however, this practice was later discontinued. It is clear from the renewed relatively common occurrence of symptomatic vitamin $\mathrm{D}$ deficiency in young infants in Johannesburg that the practice of vitamin D supplementation of all infants should be re-initiated. Furthermore, toddlers and young children in the inner city areas of Johannesburg should be considered as high risk and, therefore, supplementation should be continued for this group at $600 \mathrm{IU} /$ day. This group of high-risk children is also at risk of dietary calcium deficiency, which aggravates and accentuates the risk of nutritional rickets. Although there is limited information on the vitamin D status of pregnant mothers in SA, indications from a study at Chris Hani Baragwanath Academic Hospital are that the prevalence of vitamin D deficiency is high (Velaphi S, unpublished data); therefore, attention should be given to providing all mothers with a vitamin D supplement of $600 \mathrm{IU} /$ day during pregnancy to ensure that infants at birth are born vitamin $\mathrm{D}$ replete.

In conclusion, the guidelines recommend that all infants in SA should receive vitamin D supplements, while in the older age groups, those who are at high risk of rickets should be targeted. All pregnant mothers should also receive vitamin $\mathrm{D}$ as part of their micronutrient supplements.

\section{John M Pettifor}

MB BCh, FCPaed (SA), PhD (Med), MASSAf Editor, South African Journal of Child Health

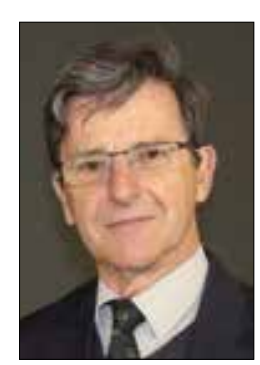

\section{References}

1. Schoenmakers I, Pettifor JM, Pena-Rosas JP, et al. Prevention and consequences of vitamin D deficiency in pregnant and lactating women and children: A symposium to prioritise vitamin D on the global agenda. Steroid Biochem Mol Biol 2015;pii:S0960-0760(15)30130-8. [http://dx.doi.org/10.1016/j. jsbmb.2015.11.004]

2. Munns CF, Shaw N, Kiely M, et al. Global consensus recommendations on prevention and management of nutritional rickets. J Clin Endocrinol Metab 2016:101(2):394-415. [http://dx.doi.org/10.1210/jc.2015-2175]

3. Munns CF, Shaw N, Kiely $M$, et al. Global consensus recommendations on prevention and management of nutritional rickets. Horm Res Paediatr 2016;85(2):83-106. [http://dx.doi.org/10.1159/000443136]

4. Pettifor JM, Moodley GP, Hough FS, et al. The effect of season and latitude on in vitro vitamin D formation by sunlight in South Africa. S Afr Med J 1996;86(10):1270-1272. 


\section{EDITORIAL}

5. George JA, Norris SA, van Deventer HE, Pettifor JM, Crowther NJ. Effect of adiposity, season, diet and calcium or vitamin D supplementation on the vitamin D status of healthy urban African and Asian-Indian adults. Br J Nutr 2014;112(4):590-599. [http://dx.doi.org/10.1017/50007114514001202]

6. Martineau AR, Nhamoyebonde S, Oni T, et al. Reciprocal seasonal variation in vitamin D status and tuberculosis notifications in Cape Town, South Africa.
Proc Natl Acad Sci USA 2011;108(47):19013-19017. [http://dx.doi.org/10.1073/ pnas.1111825108]

S Afr J Child Health 2016;10(1):3-4. DOI:10.7196/SAJCH.2016.v10i1.1165 